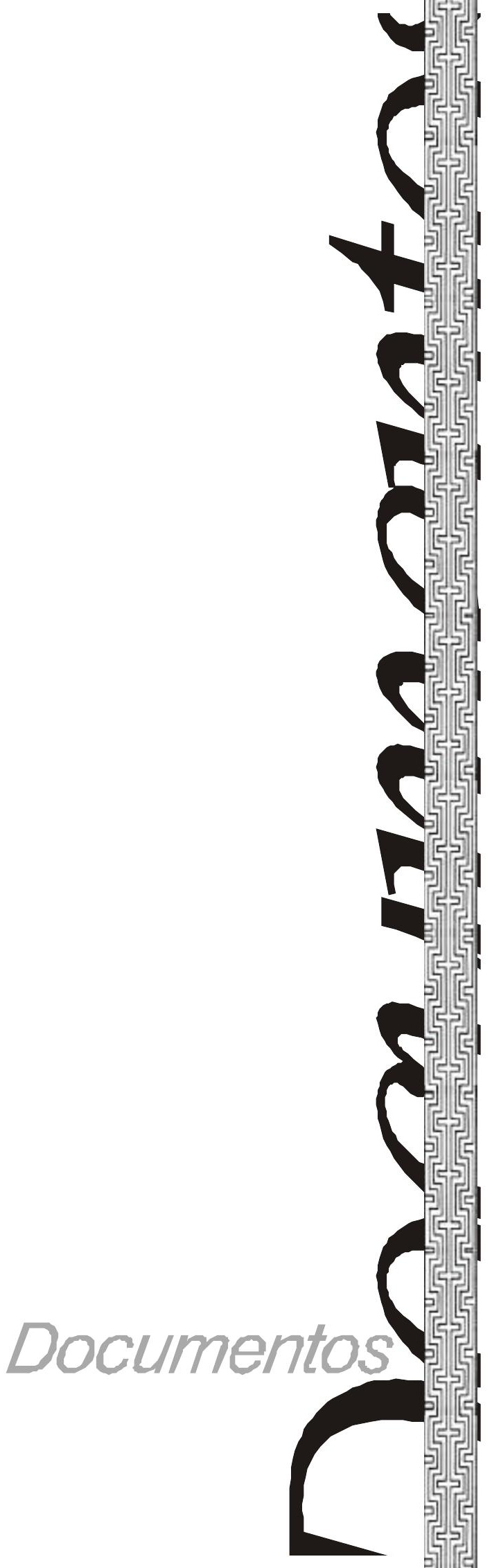





\section{Situação dos detentos indígenas no Estado de Mato Grosso do Sul}

Andréa Flores

O projeto intitulado "Situação dos detentos indígenas no Estado de Mato Grosso do Sul" foi realizado pelo Centro de Trabalho Indigenista (CTI) e Universidade Católica Dom Bosco (UCDB) com recursos da União Européia (UE). O objetivo de tal pesquisa foi fazer um levantamento de processos criminais, em andamento ou findos, em que os réus fossem indígenas detentos. A análise teve por objeto 103 processos. Após o estudo processual, as equipes procederam ao levantamento de campo nas comunidades indígenas dos envolvidos, bem como, visitas aos estabelecimentos prisionais para entrevistas com detentos e com alguns profissionais que atuaram nos processos ou prisões.

\section{Resultados obtidos:}

- Natureza da detenção:

- Não informado $=04 \%$

- Prisão em flagrante $=63 \%$

- Prisão preventiva $=28 \%$

- Proveniente de sentença condenatória $=03 \%$

- Prisão temporária $=01 \%$

- Outro $=01 \%$

- Lugar do crime:

- Comunidade do detento $=78 \%$

- Em outra comunidade $=06 \%$

- $\mathrm{Na}$ cidade $=10 \%$

- Outro local $=05 \%$

- Não informado $=01 \%$

Coordenadora do projeto; doutora em Direito das Relações Sociais, pela PUCSP, professora da graduação e da pós-graduação da UCDB. A equipe interdisciplinar que realizou a pesquisa de campo foi constituída por Andréa Flores, Antônio Jacó Brand, leda Marques, Lamartine dos Santos Ribeiro, Levi Marques, Maucir Pauletti e Nádia Heusi. flores@ucdb.br 
- Se foi reconhecido como indígena no processo

- $\underline{\operatorname{Sim}=97 \%}$

- Não $=3 \%$

- Se aparece como indígena pelo órgão responsável pela prisão

- $\underline{\operatorname{Sim}=97 \%}$

- Não $=3 \%$

Comentário: Nos processos que analisamos, há, desde a fase policial, o apontamento do autor do fato como indígena, mas isto porque os crimes geralmente são praticados dentro da aldeia. Sendo assim, a própria autoridade indígena conduz o suposto autor do fato até a Delegacia de Polícia. Mas é necessário ressaltar que, nos documentos preenchidos nas delegacias, como, por exemplo, a "ficha de vida pregressa" não há campo para o preenchimento desta informação.

- Testemunhas

- Não indígenas $=4 \%$

- Indígenas $=96 \%$

- Vítima

- Mesma etnia $=55 \%$

- Etnias distintas $=4 \%$

- Não indígenas $=16 \%$

- Não informado $=25 \%$

Obs.: há processos em que não há uma vítima (ex.: tráfico de drogas)

Comentário: Os números acima reforçam os dados de que a grande maioria dos crimes acontecem na aldeia envolvendo familiares e amigos.

- Acompanhamento

- Defensoria Pública $=67 \%$

- FUNAI $=22 \%$

- Advogado particular $=9 \%$

- Outro $=2 \%$ Conselho Tutelar (adolescente)

Comentário: Percebe-se uma deficiência da Funai, pois o Estado conta com poucos procuradores proporcionalmente ao número de indígenas. 


\section{- Acompanhado por advogado nos interrogatórios}

- Não $=6 \%$

- Sim, na fase policial $=6 \%$

- Sim, ambas as fases $=10 \%$

- $\underline{\text { Sim, }}$, somente fase judicial $=78 \%$

Comentário: Em grande parte dos casos, o indígena é conduzido até a autoridade policial por chefes da aldeia. Embora conste na maior parte dos interrogatórios que o indígena dispensa a presença de advogado, o que se sabe é que a eles não é oportunizado o acompanhamento de um profissional.

\section{Exemplo 1: Relatório de Processo}

Foro de Dourados

3- Vara Criminal

Carta de guia

Estupro

Réu: Arnaldo Ribeiro

Vítima: Daiane Quevedo Moreira

O réu foi denunciado por ter, no dia 19/4/02, por volta das duas horas, na Aldeia Amambai, constrangido a vítima, Daiane Quevedo Moreira, de apenas nove anos de idade, a manter conjunção carnal, mediante violência e grave ameaça.

No interrogatório realizado na polícia, quando da prisão em flagrante do réu, constou que o interrogando "dispensa a presença de Advogado." No interrogatório realizado em juízo, constou que "Tem advogado na pessoa do Dr. Luiz Cesar de Azambuja Martins, que deverá ser intimado para apresentar defesa prévia no prazo legal."Portanto, o réu não foi acompanhado em nenhum dos momentos em que foi ouvido.

A defesa técnica do acusado pugnou pela nulidade do interrogatório do réu, mas o juiz, Dr. Albino Coimbra Neto, não acatou a preliminar alegando que os fatos narrados na denúncia foram comprovados mediante outras provas, visto que o acusado negou a autoria dos fatos, argumentando que: "sob qualquer ângulo não se depreende prejuízo à defesa pela inobservância à formalidade legal de ter sido colhido o depoimento do réu (indígena) sem a presença de curador."

O réu foi condenado irrecorrivelmente a oito anos e nove meses de reclusão em regime fechado, mas atualmente encontra-se cumprindo a pena em regime semi-aberto. 
- Há controvérsias quanto à autoria do crime?

- Réu confessou $=23 \%$

- Réu confessou somente na fase policial $=35 \%$

- Réu confessou somente em juízo $=6 \%$

- Réu confessou em ambas as fases $=31 \%$

- Réu negou a autoria $=5 \%$

Comentários: Em razão de não haver acompanhamento de um advogado ou Procurador da Funai na fase policial, o indígena confessa em seu interrogatório, mas instruído por um profissional na fase judicial muda a versão, apresentando novos fatos.

\section{- Situação Processual:}

- Condenado, em livramento condicional $=4 \%$

- Condenado, cumprindo pena no fechado $=45 \%$

- Condenado, cumprindo pena no aberto $=6 \%$

- Condenado, cumprindo pena no semi-aberto $=12 \%$

- Processado e preso provisoriamente $=8 \%$

- Processado e solto $=10 \%$

- Preso e aguardando júri $=15 \%$

Comentário: Tendo em vista que a maioria dos crimes praticados são considerados hediondos, o regime de cumprimento que se impõe é o fechado.

\section{- Crimes/Tipificações}

Tráfico de Drogas (art. 12 da Lei 6.368/76 ou art. 33 da lei 11.343/ 06) $=11 \%$

Porte de arma (art. 14 da Lei 10.826/03) $=1 \%$

Homicídio $($ art. 121) $=37 \%$

Homicídio tentado (art. 121 c.c art. 14, II) = 3\%

Lesão corporal (art. 129) $=4 \%$

Ameaça (art. 147) = 1\%

Furto (art. 155) $=3 \%$

Roubo (art. 157) $=6 \%$

Ocultação de cadáver (art. 211) $=2 \%$

Estupro (Art. 213) $=16 \%$

Atentado violento ao pudor (art. 214) $=7 \%$

Crime sexual por presunção de violência (Art. 213 ou Art.214 c.c art. 224) $=4 \%$ 
Crime sexual com aumento de pena por ser parente da vítima (Art. 213 ou Art. 214 c.c Art. 226) = 04\% (Somatória dos crimes sexuais = 31\%) Falso testemunho $($ art. 344$)=1 \%$

Comentário: Destacam-se os crimes sexuais e homicídios. Em entrevistas com pessoas da comunidade tivemos a informação de que outros crimes também são praticados nas aldeias, mas tais delitos são resolvidos internamente usando-se o poder de polícia dos chefes de aldeia. Destaca-se um caso específico em que se demonstra a atuação da autoridade indígena.

\section{Exemplo 2: Relatório de Processo}

Foro de Ponta Porã

Vara Criminal

Tentativa de Homicídio

Réu: Osvaldo Ribeiro

Vítima: Leia da Silva

O réu foi denunciado por tentativa de homicídio simples, por ter na data de 30 de outubro de 2006, na Aldeia Marangatu, provocado lesões na sua esposa.

O Delegado de Polícia representa pela decretação da prisão preventiva do autor do fato, o que foi deferido pelo juiz. Diante das inúmeras e reiteradas agressões que o réu praticou contra sua esposa, o Conselho Disciplinar e Representante da Comunidade Local assim se manifestou: "Vem por este levar ao conhecimento do Sr. Delegado da Policia Civil de Antonio João-MS que a partir de hoje entregamos em suas mãos, ou seja, para que seja punido nas leis do brancos o indígena OSVALDO RIBEIRO a qual já foi autuado por furtos por duas vezes e por espancar a sua cônjuge, mas que conforme as nossas culturas toleraríamos por três vezes, mas agora que ele voltou a espancar a sua esposa, cuja ela a recém ganhou nenê pois nós tememos que se continuar com ele correremos o risco dele acaba matando a mãe e a criança. Pois sabemos muito bem que agora existe a lei Maria Penha lei que protege as nossas mulheres e assim esperamos que o acusado seja enquadrado nesta lei. Esperamos assim contarmos com a sua ajuda."

No recebimento da denúncia o juiz determinou que fosse notificado o Procurador da Funai para o acompanhamento do acusado, mas diante da ausência deste no interrogatório, foi acompanhado no ato pela Defensoria Pública. O processo está em andamento, na fase de instrução, o réu se encontra preso. 
- Há evidências de bebidas alcoólicas

- Não $=42 \%$

- Autor alcoolizado $=21 \%$

- Vitima alcoolizado $=1 \%$

- Autor e vítima alcoolizados $=36 \%$

Comentário: Percebe-se a grande influência do uso de bebidas alcoólicas na prática dos crimes que acontecem em festas ou dentro de casa e envolvem pessoas da mesma família ou amigos.

- Presença de intérprete ou outro meio eficaz p/ compreensão. (art. 12 da 169 (...) Medidas deverão ser tomadas para garantir que os membros desses povos possam compreender e se fazerem compreender em processos legais, proporcionando-lhes, se necessário, intérpretes ou outros meios eficazes)

$-\operatorname{Sim}=22 \%$

- Não $=78 \%$

Comentário: Cumpre ressaltar que, em parte dos processos, constatamos a presença de um intérprete, mas tal pessoa tratava-se do próprio indígena que havia conduzido o indígena infrator até a autoridade pública. Portanto, tratava-se de um intérprete parcial que poderia influir na interpretação dos fatos. Também é válido apontar que em alguns casos a figura do intérprete é dispensada sob o argumento de que o indígena fala a língua portuguesa. Ocorre que "falar a língua portuguesa" não significa que o indígena consiga numa situação de estresse como é um interrogatório entender e se fazer entender. Destaca-se abaixo o relatório produzido na análise de um processo em especial:

\section{Exemplo 3: Relatório de Processo}

Foro de Bataguassu

Vara única

Guia de Recolhimento

Homicídio qualificado

Ré: Rosalina Vasques

Vítima: Iolanda Vasques

A ré foi denunciada por ter, no dia 29 de novembro de 2002, por volta das 21 horas, na Aldeia Amambaí, desferido contra a vítima 
Iolanda Vasques, sua irmã, um golpe de facão que atingiu seu pescoço, causando-lhe a morte.

Interessante ressaltar que a ré foi ouvida na polícia sem a presença de intérprete. Ao ser interrogada em juízo, a juíza, Dra. Luciane Bunasso de Oliveira, percebeu que a acusada não fala português, afirmando: "não foi possível compreender o que esta dizia, tendo afirmado que fala guarani", motivo pelo qual redesignou a audiência para que fosse nomeado um intérprete. Posteriormente, foi ouvida em juízo na presença de um intérprete. Na sentença de pronúncia, o juiz, Dr. Thiago Nagasawa Tanaka, alega que a ré "fala bem a língua portuguesa, o que demonstra a sua integração a nossa cultura", baseando-se no depoimento de uma testemunha. Na sessão do Tribunal do Júri a ré foi ouvida também através de intérprete.

Ao ser pedida a progressão para o regime semi-aberto, a CTC (Comissão Técnica de Classificação) deu parecer favorável levando em consideração o fato de ser indígena: " Diante da problemática cultural que envolve o povo indígena, acredita-se que o retorno á sua aldeia torna-se a saída mais viável á avaliada, já que lá residem seus familiares e poderá retomar atividade produtiva. Todavia, a orientação profissional torna-se necessária, para que a reintegração social possa ocorrer de forma mais facilitada".

A ré foi condenada a 13 anos e oito meses de reclusão em regime fechado. A defesa foi patrocinada pelo Procurador da Funai, Dr. Luiz Cesar Azambuja. Atualmente cumpre pena em regime semi-aberto.

- Preferência ao não encarceramento aparece na definição da pena. (art. 10 da 169 - Dever-se-á dar preferência a tipos de punição que não o encarceramento)

$-\operatorname{Sim}=1 \%$

- Não $=99 \%$

Comentário: O que se percebeu da análise do material colhido é um grande desconhecimento por parte dos operadores do direito quanto às normas da Convenção 169 da OIT. Em apenas uma sentença o juiz fixou regime de semi-liberdade para que o indígena cumprisse a pena, prestando serviço num Posto da Funai.

- Se levou em conta as formas de punir que acontecem na comunidade, (art. 9 da 169 - Desde que compatíveis com o sistema jurídico nacional e com os direitos humanos internacionais reconhecidos, deverão ser respeitadas as medidas a que tradicionalmente recorrem esses povos para punir delitos cometidos por seus membros. Nesses casos, autoridades e tribunais solicitados a se pronunciarem sobre questões penais deverão levar em conta os costumes desses povos) 
$-\operatorname{Sim}=1 \%$

- Não $=99 \%$

- Alguns processos ainda não foram concluídos, motivo pelo qual não tem sentença.

Comentário: O que se percebeu da análise do material colhido é um grande desconhecimento por parte dos operadores do direito quanto às normas da Convenção 169 da OIT. Sendo assim, muitas vezes, a defesa sequer pleiteia que esta seja aplicada e o processo não colhe tais informações para que posteriormente o juiz as possa levar em consideração no momento da aplicação da pena.

- Houve solicitação de perícia?

- Não $=67 \%$

- Sim, sendo:

Psicológica $=17 \%$

Psiquiátrica $=4 \%$

Antropológica $=12 \%$

Comentário: Em grande parte dos processos analisados não há solicitação de perícia. Em alguns, embora a defesa tenha pleiteado, o juiz entendeu ser desnecessária a realização dos exames, por entender ser evidente $o$ dito "aculturamento" do indígena.

Recebido em 11 de fevereiro de 2008.

Aprovado para publicação em 18 de fevereiro de 2008. 